\title{
Chapter 13
}

\section{Toxicity induced alterations as biomarker of environmental pollution}

\section{Kirandeep Kaur ${ }^{1, *}$ and Arvinder Kaur ${ }^{2}$}

\section{Chapter contents}

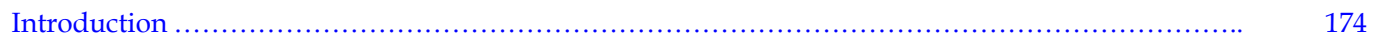

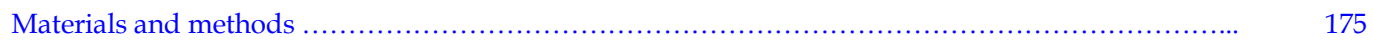

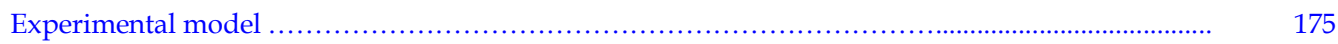

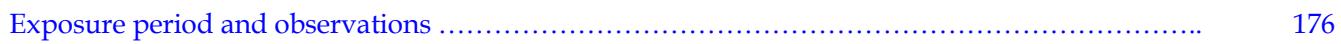

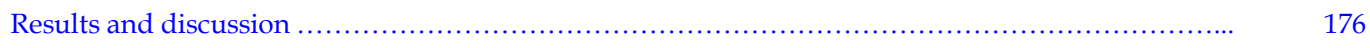

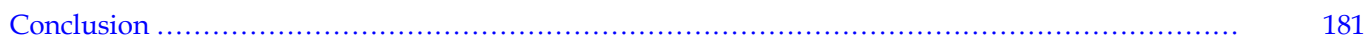

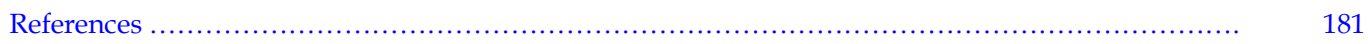

\begin{abstract}
Over the past few decades dye contamination of aquatic systems has attracted the attention of several investigators both in the developed and developing countries of the world. A large quantity of these dyes enters aquatic bodies from time to time because a substantial amount of a dye (10-15\% unbound dyes) is lost in the effluent during dyeing processes. In return the aquatic bodies end up being the final destination of a large quantity of wastes from these sectors. Waste waters from dye manufacturing, paper, leather and textile industries bring tons of dyes into the aquifers, most of which are highly toxic to the flora and fauna of the receiving water bodies. Scanning electron microscopic observations were made for the changes in the surface ultra morphology of gills of Cirrhinus mrigala on exposure to lethal $(0.1,0.2,0.4,0.6$ and $0.8 \mathrm{mg} / \mathrm{L}$ dye) doses of Basic Violet-1 (an important textile and hair colorant; CI: 42535, Trade name- Methyl Violet-2B). Present study was taken up as insufficient data exist regarding safety of this dye. The dye was observed to be cytotoxic in nature during the acute (96h) exposure to lethal doses. The dye caused reduction or complete loss of microridges, increase in mucous openings and
\end{abstract}

凶 Kirandeep Kaur, Email: kkirandeep575@gmail.com

1 Department of Zoology, Khalsa College, Amritsar-143005 (Punjab), INDIA

2 Department of Zoology, Guru Nanak Dev University, Amritsar-143005 (Punjab), INDIA

(C) 2019 | Agro Environ Media | Agriculture and Environmental Science Academy, Haridwar, India 
degeneration of gill lamellae and rakers. Therefore, time to time monitoring of ultra morphology of tissues will provide us early indicators for the stress of very low levels of pollutants which may later cause mortality of the fish. The study holds importance because fishes are an important link in the food chain of man, respond to toxicants in a manner similar to higher vertebrates causing serious diseases.

Keywords: Acute exposure, Cirrhinus mrigala, Gills, Scanning electron microscopy, Ultra morphology

\section{Introduction}

Aquatic ecosystems are of extreme importance for the world population, as these are used for domestic, agricultural, industrial as well as recreational activities. In return the aquatic bodies end up being the final destination of a large quantity of wastes from these sectors. Waste waters from dye manufacturing, paper, leather and textile industries bring tons of dyes into the aquifers, most of which are highly toxic to the flora and fauna of the receiving water bodies (McCarthy, 1997). Uncontrolled discharge of dyes in water bodies causes serious problems due to change in colour of the water and production of even more toxic by-products after reduction in light (Chung, 1983). As a result, various dyes are banned and maximum residue levels exist in Europe and USA, however, in several other countries of the world, these dyes are openly sold in the market without any information regarding their chemical nature, purity, toxicity and possible mutagenicity (Mathur et al., 2005). Unregulated use of dyes will therefore have grave consequences for human health and aquatic ecosystems in these countries. The aquatic environment is of primary concern because many a times these various toxic chemicals not only have significant implications for long-term survival of natural populations of the organisms living therein but cause heritable mutations that may lead to loss of the total genetic diversity of an ecosystem.

Many industries releasing industrial wastes and effluents contain various levels of organic and inorganic pollutants including acids, alkalis, inorganic ions, heavy metals etc. are one of the major sources of environmental pollutants in India. They discharge their effluents directly or indirectly into rivers and agricultural land used to irrigate agricultural fields, make the water and soil polluted, which is not good for agricultural purposes (Samanta et al., 2018). The industries utilize many poisonous substances, which are very harmful to the plants and soil microorganism. The river water polluted with industrial effluent contains various toxic chemicals, dyes and heavy metals such as mercury (Hg), Cadmium (Cd), Chromium (Cr) and Zinc ( $\mathrm{Zn})$. When the effluent is used for irrigation, these metals are strongly bound to polypeptide and proteins of aquatic plants and animals. Of all the aquatic organisms fish have become vulnerable indicators for evaluation of the effects of such noxious compounds (Khidr and Mekkawy, 2008; Kaur and Dua, 2015) as these are the ultimate sufferers of pollution and form an important link in the food chain of humans. 
By virtue of their high reactivity, dyes and other genotoxins contribute to structural modifications in the DNA of fish which then become the underlying cause of metabolic dysfunction and death. These disturbances being irreversible are transmitted to the future generations, have long lasting effects and appear even at those levels of toxins which are otherwise safe for survival.

Although light microscopic studies provide good information about stress induced alterations in the cell morphology under stress but for obtaining finer and early details of the underlying causes of the death, electron microscopic technique-Scanning electron microscopic (SEM) studies for detailed information about the surface morphological variations in gills is preferred. Use of electron microscopy in relation to pollution and environmental conditions is a recent approach and is considered a very useful tool as it adds a valuable third dimension for understanding the structural deformations as well as for obtaining information much before fish exhibit many other visible symptoms of toxicity (Hidayati et al., 2013). Therefore, in the present study electron microscopy (SEM) has been used collectively for evaluating toxicity of Basic Violet-1 (a triphenylmethane dye) because toxicity data for this dye is not available (Diamante et al., 2009). Dyes with triphenylmethane pharmacophore (Basic Violet-1, Gentian Violet, Crystal Violet) have a long history of human use (Souza Pietra et al., 2013) but these interact with lipid bilayers of the cellular membrane and perturb membrane structure as well as ionic balance of the cell (Dell Antoneet al., 1972; Aljofan et al., 2009). In living systems these are biotransformed to demethylated derivatives which react with DNA and lead to tumour development (Culp et al., 2006). Present work envisages evaluation of toxic potential of Basic Violet-1 (BV-1, CI:42535: Trade name- Methyl Violet-2B) which is commonly used as a direct synthetic (non oxidative dye) fibre/ textile dye and a hair colorant (Diamante et al., 2009). Cirrhinus mrigala, an Indian Major Carp, abundantly present in fresh waters of India has been selected as a test model for this studyto detect most prominent changes in in the epithelial cells and morphology of the gillsthat can act as a biomarker for the stress of very low doses of such dyes. Predominantly, the gills constitute a multifunctional organ (respiration, acid base regulation, ionregulation, nitrogenous waste excretion) accounting for well over fifty per cent of the total surface area of the animal. They are the major site of uptake for most water bone toxicants and site of toxic impact for many of them. (Ale et al., 2018).

The main aim was to assess the suitability of ultramorphological changes in the pavement cells, chloride cells, and mucous openings in the gill as early indicators of the dose dependent stress of Basic Violet-1. This research work has been envisaged as insufficient data exist to support the safety for this dye (Diamante et al. 2009).

\section{Materials and methods}

\section{Experimental model}

For the present study C. mrigala was selected as a model for evaluating acute toxicity of a dye, BV-1. 
Procurement and acclimation of fish: Fish weighing $22 \pm 1.25 \mathrm{~g}$ and measuring $10.50 \pm 1.22 \mathrm{~cm}$ were procured from the Government Fish Farm, Rajasansi, Amritsar, Punjab, India. The fish were given a bath in $0.1 \% \mathrm{KMnO}_{4}$ for 2-3 minutes for disinfection, diseased fish were sorted and not subjected to experimentation. Fish were acclimated for 21 days under laboratory conditions and fed with a pelleted commercial Toya feed on alternate days @ $2 \%$ of the biomass.

Toxicant used: BV-1 (CI: 42535), purchased from the local market, Amritsar, India was used for the present study. The commercial grade preparation was a green coloured powder soluble in water.

Test containers: Toxicity tests were conducted in plastic pools of $200 \mathrm{~L}$ capacity.

Dilution water and control: Dechlorinated tap water was used as control and for making various concentrations of the dye.

\section{Exposure period and observations}

Acute exposure: Ten fish were exposed in triplicate to 0, 0.10, 0.20, 0.40, 0.60, 0.80 and $1.0 \mathrm{mg} / \mathrm{L}$ dye. Semi static daily renewal 96h bioassay was conducted according to OECD guidelines (1992) and APHA (1998). No food was given 24h prior to the exposure during the bioassay. Mortality was recorded at $24 \mathrm{~h}$ intervals and dead fish were removed immediately to avoid asphyxiation of other fish. A fish was considered dead when no opercula movement was there and it did not move on prodding with a glass rod.

Observations: Observations were recorded at the beginning and at the end of the acute exposure for ultra morphological changes (scanning electron microscopic studies on gill) in the fish during the study.

Gill: Second and third gill arch from the right side were immediately excised and fixed in the Karnovsky's fixative for $6-12 \mathrm{~h}$. Post fixation was done in $1 \%$ Osmium tetraoxide for $2 \mathrm{~h}$ at $4^{\circ} \mathrm{C}$. Three washings were given in $0.1 \mathrm{M}$ phosphate buffer ( $\mathrm{pH} 7.4$ ), and dehydration of the sample was carried for 15 min each in 30, 50, 70, 90 and 100\% anhydrous alcohol. The dehydrated tissue was critical-point dried and placed over the silver tape attached to the aluminium stub.

Coating and viewing: Gold coating of the samples was done with a sputter coater [Model: Q150RES (QUORUM)] for viewing under Carl Zeiss EVO|LS 10, Scanning electron microscope at The Central Instrumentation Facility, Guru Nanak Dev University, Amritsar and Carl Zeiss EVO|MA 10 at The Indian Agricultural Research Institute, New Delhi at low acceleration voltage of $10-20 \mathrm{kV}$. Till the time of viewing, the stubs were kept in a desiccator.

\section{Results and discussion}

For evaluating toxicity of Basic Violet-1, fingerlings of C. mrigala were given acute (96h) exposures to BV-1. Data were recorded for ultra structural changes in the gills of fish during the exposure period. C. mrigala has four pairs of lateral gills which are reddish in colour and protected by an operculum. Each gill arch bears two rows of primary filaments upon which are situated two rows 
of secondary lamellae. Gill filaments, lamellae and rakers were found to be lined by pavement cells (simple squamous epithelial cells) which were polygonal or hexagonal in shape. A single or double ridged border (Micro border) was seen between pavement cells or pavement cell and chloride cell junction. The dye induced changes in the morphology of filaments, lamellae as well as rakers of the gill. Two rows of stiff denticular gill rakers are present on the other side of gill arch. The microvilli or micro ridges overlying the pavement cells of the gill arch, primary filament and secondary lamella showed considerable disorganization with respect to their size and shape in the dye exposed fish.

On exposure to different concentrations of the dye, there was no change in gill morphology of control (after 96h) and $0.10 \mathrm{mg} / \mathrm{L}$ dye exposed fish (after the acute exposure) in the present study (Figure 13.1a-b).No change was observed in the gillrakers of control and $0.10 \mathrm{mg} / \mathrm{L}$ dye exposed fish as they were spaced equally (Figure 13.1c) while a dose dependent increase was observed during the acute exposure. Microridges of pavement cells of primary and secondary gill lamellae of control and $0.10 \mathrm{mg} / \mathrm{L}$ dye exposed fish were observed to be shorter, interwoven and random-
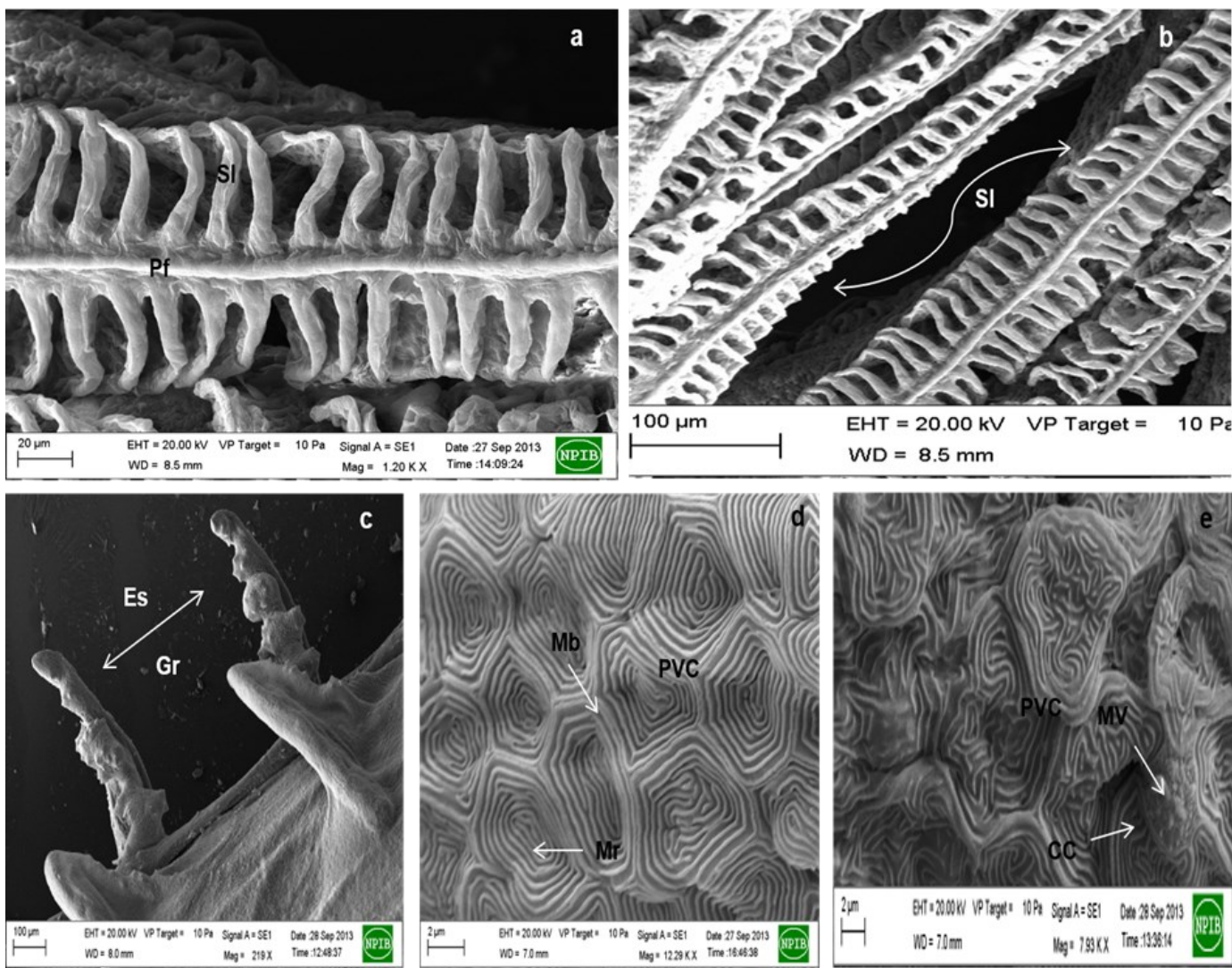

Figure 13.1. Gills of control C. mrigala after 96h exposure (a-e); Pf - Primary gill filament, Sl-Secondary lamellae, GR-Gill rakers, Es-Equally spaced, PVC-Pavement cells, Mr-Microridges, Mb-Microborder, CC-Chloride cells, $M V$ - Microvilli. 
ly oriented at the beginning as well as at the end of exposure as well as microvilli of chloride cells were observed to be normal (Figure 13.1d-e).

There was a dose dependent loss of secondary lamellae and collapse of structural integrity of the epithelial cells after $96 \mathrm{~h}$ exposure. On exposure to 0.20 and $0.40 \mathrm{mg} / \mathrm{L}$ dye, fusion of secondary lamellae (Figure 13.2a) initiated while in $0.60 \mathrm{mg} / \mathrm{L}$ dye, mucous cell openings and sloughing of the epithelium of primary gill filaments at tips was also observed at some places (Figure 13.2b-c). In $0.80 \mathrm{mg} / \mathrm{L}$ dye, mucous cell openings, necrosis and degeneration of epithelium on the secondary gill lamellae were noticed all over the gill surface (Figure 13.2d).

Alteration in the shape of the microridges started appearing in 0.20 and $0.40 \mathrm{mg} / \mathrm{L}$ dye and became more pronounced with the increase in dose (Figure 13.3a). Mucous cell openings and gall like structures were noticed in some of the pavement cells on exposure to $0.60 \mathrm{mg} / \mathrm{L}$ dye which increased further in $0.80 \mathrm{mg} / \mathrm{L}$ dye and were accompanied with degeneration of microridges of the whole surface of gill (Figure 13.3a-b). Slight changes were observed in the morphology of gill rakers of fish exposed to $0.20-0.40 \mathrm{mg} / \mathrm{L}$ dye but there was a marked change in structural conformity like swelling, erosion and necrosis of the surface of rakers on exposure to 0.60 and $0.80 \mathrm{mg} / \mathrm{L}$ dye (Figure 13.3c). There was no change in the pavement cells of the rakers of 0.20 and $0.40 \mathrm{mg} / \mathrm{L}$ dye exposed fish. Fusion of pavement cells, loss of micro ridges was also noticed in $0.60 \mathrm{mg} / \mathrm{L}$ dye along with these changes, degeneration of pavement cells, microridges and microvilli of the rakers was common in $0.80 \mathrm{mg} / \mathrm{L}$ dye (Figure 13.3d).
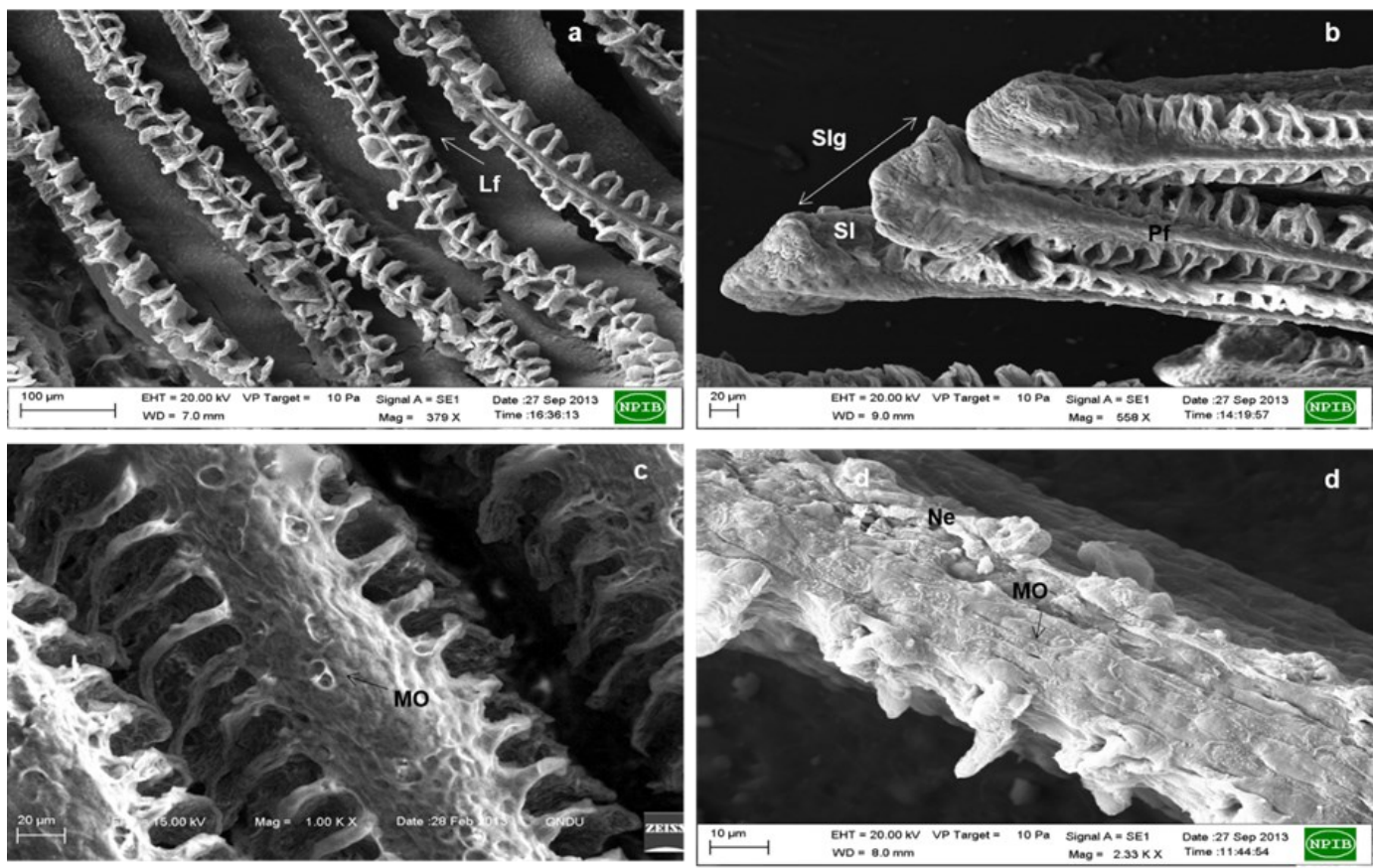

Figure 13.2. Gills of dye exposed (0.20-0.80 mg/L dye) C. mrigala (a-d); Pf-Primary gill filament, SlSecondary lamellae, Lf-Lamellar fusion, Slg-Sloughing, Mo-Mucous opening, Ne-Necrosis. 

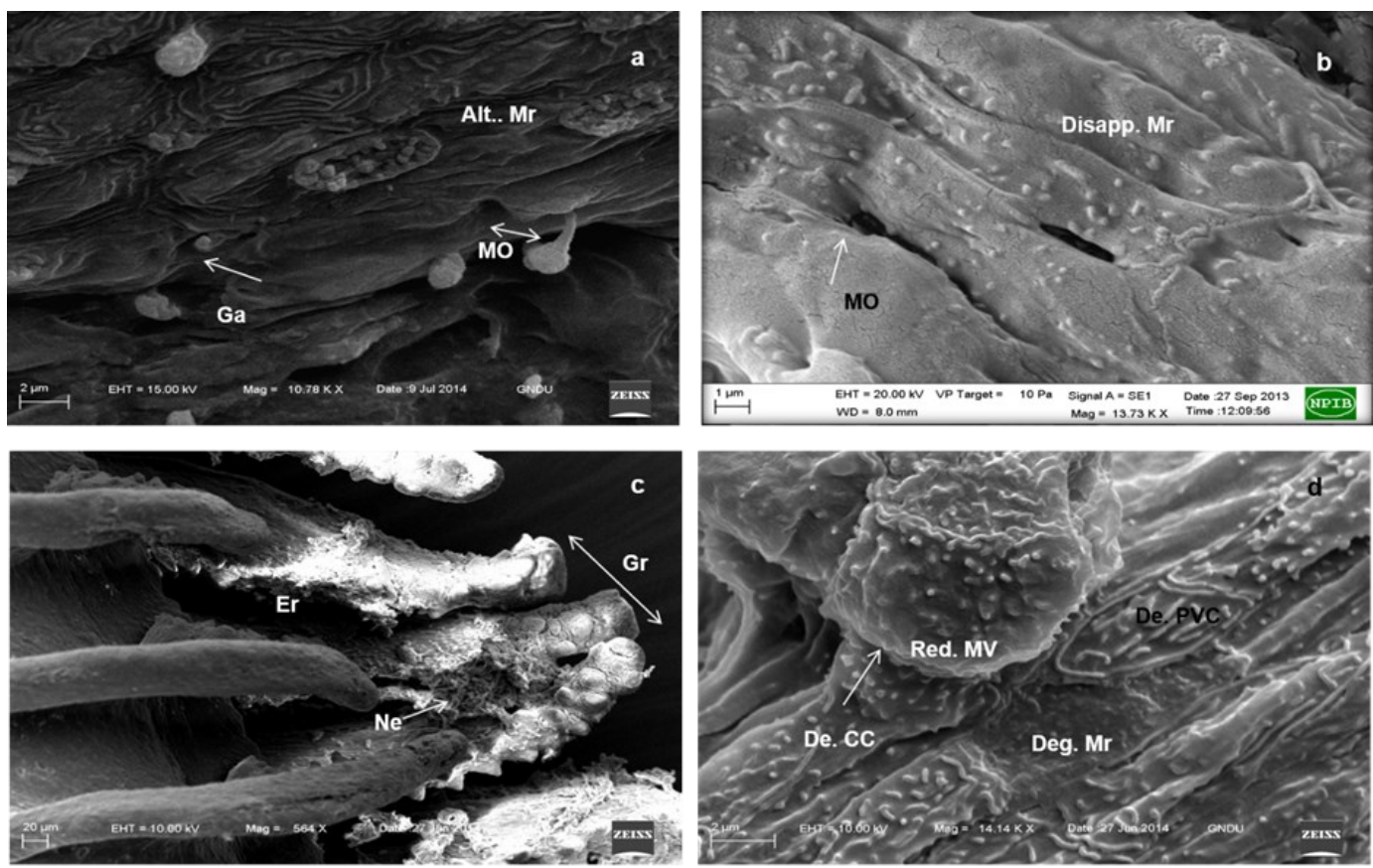

Figure 13.3. Gills of dye exposed (0.60-0.80 mg/L dye) C. mrigala showing degenreration of microridges (Pavement cells) and microvilli (Chloride cells) of lamellae and gill rakers (a-d); Alt. Mr-Alternating microridges, Ga- Gall like appearances, MO- Mucous opening, Disappear. Mr- Disappearance of microridges, Er-Erosion, Ne- Necrosis, Dr-Gill rakers, Red MV-Reduction in Microvilli, De PVC-Degenerating Pavement Cells, Deg. Mr-Degenerating microridges, De. CC-Degenerating Chloride Cells.

In the present study, ultra structural changes were observed in C. mrigala after acute (96h) exposure to BV-1. Toxic effects of the present dye on the gill of fish can be divided into two categories: lesions and reactions. Lesions, the direct and deleterious effects including necrosis and rupture of respiratory epithelium (Temmink et al., 1983) were observed to be dose dependent during acute exposure. Lesions due to the present dye may have developed either due to the stress induced autolysis by the cell's own enzymes or due to the direct cytotoxic action of the dye (Mallatt, 1985). Perturbation of membrane structure due to direct binding of the cationic dyes to lipid bilayers has been reported by Zachowski and Durand (1988). The reactions like epithelial lifting, fusion, hypertrophy, hyperplasia, increase in mucous secretion, vascular stasis, mucous cell proliferation, loss of microvilli and chloride cell proliferation (Morgan and Tovell, 1973; Mallatt, 1985; Dutta et al., 1996) are generally considered to be defensive mechanisms for reducing the surface area in contact with the toxins (Dutta et al., 1997) but in the present study these were replaced with lesions with the dose of the dye.

During the acute exposure, reactions were prominent in 0.20 and $0.40 \mathrm{mg} / \mathrm{L}$ dye but the incidence of lesions and reactions was equal in 0.60 and $0.80 \mathrm{mg} / \mathrm{L}$ dye. As a result, lesions appeared even due to very low doses of the dye with the increasing dose of exposure. Drastic changes like loss of 
structural integrity and necrosis hint towards carcinogenic or mutagenic nature of this dye. Several dyes have been reported to be carcinogenic, mutagenic and teratogenic with a potential to cause chromosomal fracture (Khanna and Das, 1991). Being water soluble, the present dye might have been degraded by anaerobic intestinal microorganisms (Chung and Stevens, 1993) and this could have activated a procarcinogen to a mutagen (McCoy et al., 1977). On the other hand, dose dependent increase in extrusion of mucous, epithelial lifting, lamellar fusion and reduction of micro ridges in lower doses of acute $(0.20$ and $0.40 \mathrm{mg} / \mathrm{L}$ dye) exposure can be considered to be defensive reactions of the dye stressed fish. Loss of microridges in fish gills under the stress of toxicants has been observed by many workers (Hart and Oglesby, 1979; Jacobs et al., 1981; Jagoe and Haines, 1983; Roy et al., 1986; Roy and Munshi, 1991). Lamellar swelling, epithelial lifting and reduction of micro ridges in the present fish may have been to reduce the surface area of the gills in contact with the dye so as to sustain the progressive loss of the basic function of the gill (Temmink et al., 1983). This may also have been to increase the barrier distance for diffusion from outside to blood capillaries (Dutta et al., 1992).

Present dye seems to be abrasive in nature as it promoted necrosis, mucous cell openings and copious mucous secretion in a dose dependent manner (Kaur and Jindal, 2016). The dose dependent increase in extrusion of mucus may have been to facilitate respiration in the dye exposed fish as mucous decreases the co-efficient of drag for water flow across the gills, reduces the resistance of gill and plays a role in ion exchange and water balance under stress (Shephard, 1994; Macirella and Brunelli, 2017). However, loss of microridge pattern and copious mucous seems to have reduced the effectiveness of exchange processes, especially gaseous exchange and further stressed the fish and caused mortality. Enormous damage to the epidermis and destruction of cell processes and nerve supply of melanophores due to absorption of Chrome Black T has been reported by Singh (2007) in Colisa chuna. Misreplication of dye induced DNA lesions after its N-hydroxylation (Culp et al., 2006) may have resulted in mutations that resulted in appearance of gall like structures in $0.60 \mathrm{mg} / \mathrm{L}$ dye after acute exposure to BV-1.

The present dye seems to affect the ionic balance of the fish as it caused erosion of rakers in some doses. Dose dependent increase in the appearance of chloride cells but reduction in their microvilli (the short and stubby microridges) during the acute exposure could also be an effort of the stressed fish for maintaining ionic balance under the influence of this cationic dye as the chloride cells or ionocytes are associated with electrolyte balance of the body. An increase in intracellular concentration of calcium and a large decrease in sodium ion concentration due to loss of cellular membrane integrity under the stress of cationic dyes have been reported by Aljofan et al. (2009). Similar changes in chloride cells have been reported by Ghanbousi et al. (2012) in Aphanius dispar exposed to deltamethrin. However, Wong and Wong (2000) reported augmentation of micro ridges in pavement cells and an increase in the density and apical membrane area of chloride cells of O. mossambicus after a short term exposure to cadmium. This highlights the significance of ultrastructural changes in gills over mortality as early indicators of the stress of cationic dyes like BV-1. 


\section{Conclusion}

The electron microscopic studies in gills will provide us early indicators of the stress of very minute doses of cationic dyes like BV-1. Therefore, time to time monitoring of ultramorphology of tissues will provide us early indicators for the stress of very low levels of pollutants which may later cause mortality of the fish. The results clearly show that BV-1 is mutagenic, carcinogenic as well as cytotoxic in nature and this effect becomes more prominent at $0.80 \mathrm{mg} / \mathrm{L}$ dye showing deleterious effects. The toxicants present in the industrial dyes or effluents when come in contact with biological environment may create serious long-term toxicity effect to the living organisms. However, the extent of toxicity depends upon their concentration and duration of exposure to the vulnerable site.

\section{Acknowledgements}

Financial support from UGC as SRF to K Kaur (Vide Letter No. F.40-50(M/S)/2009(SA-III/ MANF) and UPE to A Kaur is greatly acknowledged. We are thankful to Indian Agricultural Research Institute (IARI), PUSA, New Delhi and Central Instrumentation Facility, Guru Nanak Dev University, Amritsar for help in SEM photography.

\section{Author contributions}

The study was designed by A Kaur and provided overall supervision and management of the work. K. Kaur performed the experiment and wrote the first draft. Both the authors were involved in interpretation of results, critical evaluation, and approval of the final manuscript.

\section{Conflict of interest}

The authors declare that there are no conflicts of interest.

\section{References}

Ale, A., Bacchetta, C., Rossi, A.S., Galdoporpora, J., Desimone, M. F., Torre, F.R., Gervasio, S. and Cazenave, J. (2018). Nanosilver toxicity in gills of a neotropical fish: Metal accumulation, oxidative stress, histopathology and other physiological effects. Ecotoxicology and Environmental Safety, 148: 976-984.

Aljofan, M., Sganga, M.L., Lo, M.K., Rootes, C.L., Porotto, M., Meyer, A.G., Saubern, S., Moscona, A. and Mungall, B.A. (2009). Antiviral activity of gliotoxin, gentian violet and brilliant green against Nipah and Hendra virus in vitro. Virology Journal, 6: 187.

APHA (1998). American Standard Methods for the examination of Water and Wastewater. 20th Edition. American Publication of Health Association, Washington, DC, 2005-2605.

Chung, K.T. (1983). The significance of azo-reduction in the mutagenesis and carcinogenesis of azo dyes. Mutation Research, 114(3): 269-281. 
Chung, K.T. and Stevens, J.R. (1993). Degradation of azo dyes by environmental microorganisms and helminthes. Environmental Toxicology and Chemistry, 12: 2121-2132.

Culp, S.J., Mellick, P.W., Trotter, R.W., Greenlees, K.J., Kodell, R.L. and Beland, F.A. (2006). Carcinogenicity of malachite green chloride and leucomalachite green in B6C3F1 mice and F344 rats. Food Chemistry and Toxicology, 44: 1204-1212.

Dell Antone, P., Colonna, R. and Azzone, G.F. (1972). The membrane structure studied with cationic dyes. 1. The binding of cationic dyes to submitochondrial particles and the question of the polarity of the ion-translocation mechanism. European Journal of Biochemistry, 24: 553-565.

Diamante, C., Bergfeld, W.F., Belsito, D.V., Klaassen, C.D., Marks, J.G. Jr., Shank, R.C., Slaga, T.J., Synder, P.W. and Alan Andersen, F. (2009). Final report on the safety assessment of Basic Violet 1, Basic Violet 3 and Basic Violet 4. International Journal of Toxicology, 28(6): 193S-204S.

Dutta, H.M., Munshi, J.S.D., Roy, P.K., Singh, N.K., Adhikari, S. and Killius, J. (1996). Ultrastructural changes in the respiratory lamellae of the catfish, Heteropneustesfossilis, after sublethal exposure to malathion. Environmental Pollution, 9: 329-341.

Dutta, H.M., Munshi, J.S.D., Roy, P.K., Singh, N.K., Motz, L. and Adhikari, S. (1997). Effects of Diazinon on bluegill sunfish, Lepomismacrochirus, gills: scanning electron microscope observations. Experimental Biology Online, 2: 17-31.

Dutta, H.M., Zeno, T. and Richmonds, C. (1992). Toxic action of diazinon on the gills of bluegill sunfish Lepomismacrochirus. Ohio Journal of Science, 92: 09.

Ghanbousi, R., Baomar, T. and Victor, R. (2012). Effect of deltamethrin on the gills of Aphaniusdispar: a microscopic study. Tissue Cell, 44: 7-14.

Hart, R.K. and Oglesby, G.B. (1979). Toxin induced changes in the gill epithelium of rainbow trout (Salmo gairdneri). Scanning Electron Microscopy, 3: 355-361.

Hidayati, D., Sulaiman, N., Othman, S. and Ismail, B.S. (2013). Fish scale deformation analysis using scanning electron microscope: New potential biomarker in aquatic environmental monitoring of aluminum and iron contamination. AIP Conference Proceedings, 1571: 563.

Jacobs, D., Exmond, E.F., Melisky, E.L. and Hocutt, C.H. (1981). Morphological changes in gill epithelium of heat stressed rainbow trout, Salmo gairdneri: evidence in support of a temperature induced surface area hypothesis. Canadian Journal of Fisheries and Aquatic Sciences, 38: 16-22.

Jagoe, C.H. and Haines, T.A. (1983). Alterations in gill epithelium morphology of yearling Sunapee trout exposed to acute acid stress. Transactions of the American Fisheries Society, 112: 689-695.

Kaur, M. and Jindal, R. (2016). Sem Study of Ultrastructural Changes in Branchial Architecture of Ctenopharyngodonidella (Cuvier \& Valenciennes) exposed to Chlorpyrifos. Archives of Biological Sciences, 68(2): 393-398.

Kaur, R. and Dua, A. (2015). 96h LC 50 , behavioural alterations and histopathological effects due to wastewater toxicity in a freshwater fish Channa punctatus. Environmental Science and Pollution Research, 22: 5100-5110.

Khanna, S.K. and Das, M. (1991). Toxicity, carcinogenic potential and clinic epidemiological studies on dyes and dye intermediate. Journal of Scientific and Industrial Research, 50: 965-974.

Khidr, M.B. and Mekkawy, I.A.A. (2008). Effect of separate and combined lead and selenium on the liver of the cichlid fish Oreochromis niloticus: ultrastructural study. Egyptian Journal of Zoology, 50: 89-119.

Macirella, R. and Brunelli, E. (2017). Morphofunctional Alterations in Zebrafish (Danio rerio) Gills after Exposure to Mercury Chloride. International journal of molecular sciences, 18(4): 824 .

Mallatt, J. (1985). Fish gill structural changes induced by toxicants and other irritants: a statistical review. Canadian Journal of Fisheries and Aquatic Sciences, 42: 630-648.

Mathur, N., Bhatnagar, P., Nagar, P. and Bijarnia, M.K. (2005). Mutagenicity assessment of from textile/dye industries of Sanganer, Jaipur (India): a case study. Ecotoxicology and Environmental Safety, 61: 105-113.

McCarthy, B. (1997). Biotechnology and Coloration. Review of Progress in Coloration, 27: 26-31.

McCoy, E.C., Speck, W.T. and Rosenkranz, H.S. (1977). Activation of a procarcinogen to a mutagen by cell-free extracts of anaerobic bacteria. Mutation Research, 46: 261-264.

Morgan, M. and Tovell, P.W.A. (1973). The structure of the gill of the trout, Salmo gairdneri (Richardson). Zeitschrift der Zellforschung und Mikroskopischen Anatomie, 142: 147-162.

OECD. (1992). Test No. 203: Fish, Acute Toxicity Test, OECD Guidelines for the Testing of Chemicals, Section 2, OECD Publishing.

Roy, P.K. and Munshi, J.S.D. (1991). Malathion induced structural and morphometric changes of gills of a freshwater major 
carp, Cirrhinus mrigala (Ham.). Journal of Environmental Biology, 12: 79-87.

Roy, P.K., Munshi, J.S.D. and Munshi, J.D. (1986). Scanning electron microscopy evaluation of effects of saponin on the gills of the climbing perch, Anabas testudeneus (Bloch) (Anabantidae: Pisces). Indian Journal of Experimental Biology, 24: 511-516.

Samanta, P., Das, R., Pal, S., Mukherjee, A., Senapati, T., Kole, D., and Ghosh, A. (2018). Toxicity assessment of agrochemical Almix in Heteropneustes fossilis through histopathological alterations, Interdisciplinary Toxicology, 11(2): 138-147, https:// doi.org/10.2478/intox-2018-0010

Shepherd, K.L. (1994). Functions for fish mucous. Reviews in Fish Biology and Fisheries, 4: 401-429.

Singh, A.K. (2007). Chrome black- T induced hyper pigmentation in the skin of an air breathing fish Colisachuna. Journal of Experimental Biology, 10(1): 99-102.

Souza Pietra, R.C.C., Rodrigues, L.F., Teixeira, E., Fried, L. and Lefkove, B. (2013). Triphenylmethane derivatives have high in vitro and in vivo avtivity against the main causative agents of cutaneous Leishmaniasis. PLOS ONE, 8(1): e51864.

Temmink, J., Bouweister, P., De Jong, P. and Vander Berg, J. (1983). An ultrastructural study of chromate induced hyperplasia in the gill of rainbow trout (Salmo gairdneri). Aquatic Toxicology, 4: 165-179.

Wong, C.K.C. and Wong, M.H. (2000). Morphological and biochemical changes in the gills of Tilapia (Oreochromis mossambicus) to ambient cadmium exposure. Aquatic Toxicology, 48: 517-527.

Zachowski, A. and Durand, P. (1988). Biphasic nature of the binding of cationic amphipaths with artificial and biological membranes. Biochemica et Biophysica Acta, 937: 411-416.

$* * * * * * *$

Cite this chapter as: Kaur, K. and Kaur A. (2019). Toxicity induced alterations as biomarker of environmental pollution. In: Kumar, V., Kumar, R., Singh, J. and Kumar, P. (eds) Contaminants in Agriculture and Environment: Health Risks and Remediation, Volume 1, Agro Environ Media, Haridwar, India, pp. 173-183, https://doi.org/10.26832/AESA-2019-CAE-0155 $-013$ 